\title{
THE IMPORTANCE OF THE PLUMMER-VINSON SYNDROME IN THE AETIOLOGY OF CARCINOMA OF THE UPPER GASTRO-INTESTINAL TRACT
}

\author{
J. McK. WatTs, M.B., B.S. \\ Registrar, Unicersity Department of Surgery, Alfred Hospital, Melbourne, Australia
}

ON May 2, 1919, at the Summer Congress of the Laryngological Section of the Royal Society of Medicine, two British laryngologists, D. R. Paterson and A. Brown-Kelly, independently read papers describing a quite specific type of dysphagia occurring usually in middle-aged women. The dysphagia, although sometimes of sudden onset, was usually of long standing and was referred to the level of the larynx. Both Paterson and BrownKelly remarked on the commonly associated atrophy of the mucosal lining of the upper gastrointestinal tract. The lesions observed were fissures at the angles of the mouth, atrophic glossitis, pale smooth pharyngeal mucous membrane and strictures or web-like deformities at the pharyngoœsophageal junction.

Brown-Kelly, in his contribution, made passing mention of a history of anæmia in some of his patients. Two years later Porter P. Vinson (1922), this time a physician at the Mayo Clinic, published a paper on what he called 'Hysterical Dysphagia'. This was primarily an affliction of women and it was noticeable that 37 of his 63 patients had hæmoglobin values of less than $60 \%$. It has since become reasonably evident that he was describing precisely the same clinical condition as were his British contemporaries; which makes it all the more surprising that he failed to note any of the abnormal changes on endoscopy of the pharynx or lesions of the mouth and tongue to which Paterson and Brown-Kelly had paid so much attention. This absence of any evident organic disease in the upper food passages led him to the conclusion that the dysphagia was an hysterical manifestation. This view was not supported by Paterson and Brown-Kelly, who considered that the dysphagia was due to spasm consequent on the local anatomical changes present at the site of obstruction.

It was on the basis of this communication alone that Vinson has come to enjoy eponymous dis- tinction. More fortunate still is Plummer, a physician colleague at the Mayo Clinic, who does not seem to have made any literary contribution on this topic and to whose interest in the condition Vinson only made passing reference in his paper. In the discussion which followed the presentation of Vinson's paper it was suggested that 'because of the fact that no other clinic has recognized this disease, it seems only fair that Dr. Vinson's name should be given to this disease'. However, not all the audience were so benevolent, for when'Dr. S. H. Boyer, of Duluth, remarked, 'the multiplicity of personal names for disease is wrong; let us not add to this but let us distinguish the doctor (Vinson) in some other manner', we are informed that his comment was greeted by applause. It must, none the less, be admitted that however strong may be our claim for the British contributors on the score of priority, we will find it hard to win a place for Paterson and Brown-Kelly. Plummer-Vinson syndrome it is, and so it is likely to remain.

It is largely to the contributions of the Scandinavian and particularly of the Swedish writers that we are indebted for our more complete understanding of this disease, if disease it deserves to be called. It is evident that there is, in Sweden, a remarkable incidence of this condition amongst the female population although in the other Scandinavian countries and in Great Britain, North America and Australia it is much less common.

The disease is almost always confined to females of middle age (contrast Figs. I and 2). The dysphagia, usually referred to the level of the larynx, is often of many year's duration and insidiously progressive. There is often complete edentia, a tight and smooth facial skin, a small mouth fissured or scarred at the angles, and fingernails which are usually brittle and sometimes spoon-shaped (Fig. I). We note that 


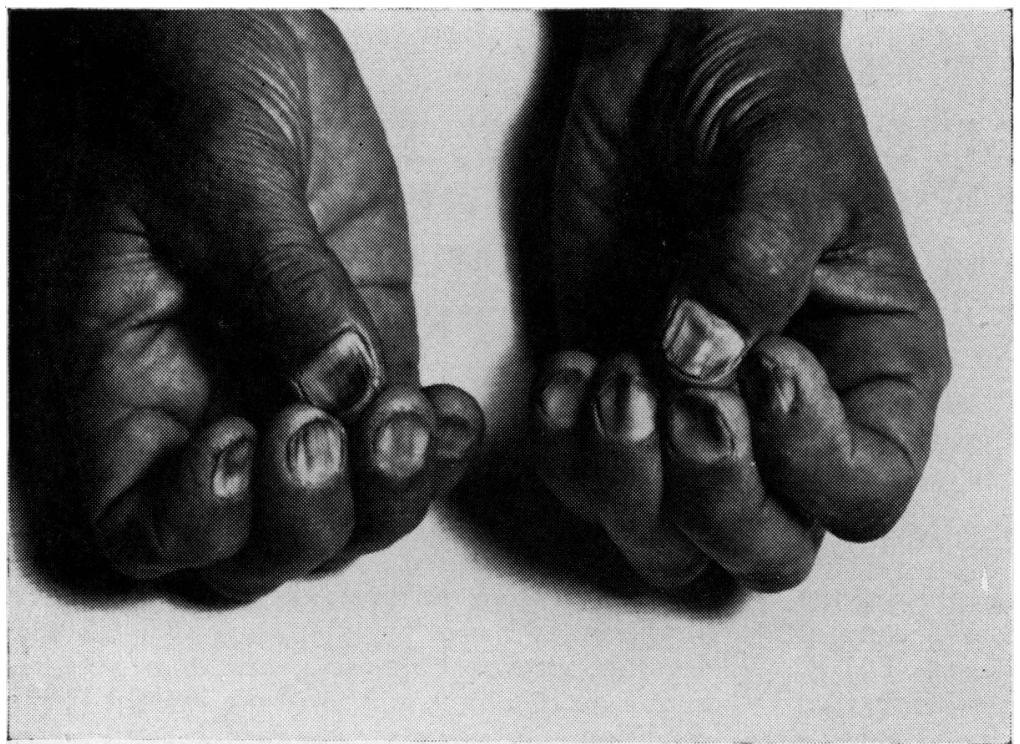

* FIG. 1.-Severe koilonychia and irregularity of the nails in male patient with PlummerVinson Syndrome.

*FIg. 2.-(Same patient as Fig. r.) After iron therapy for one year, the nails have become normal.

*Figures $\mathrm{I}$ and 2 reproduced with the kind permission of Professor Jacobson of the Radiumhemmet, Stockholm.

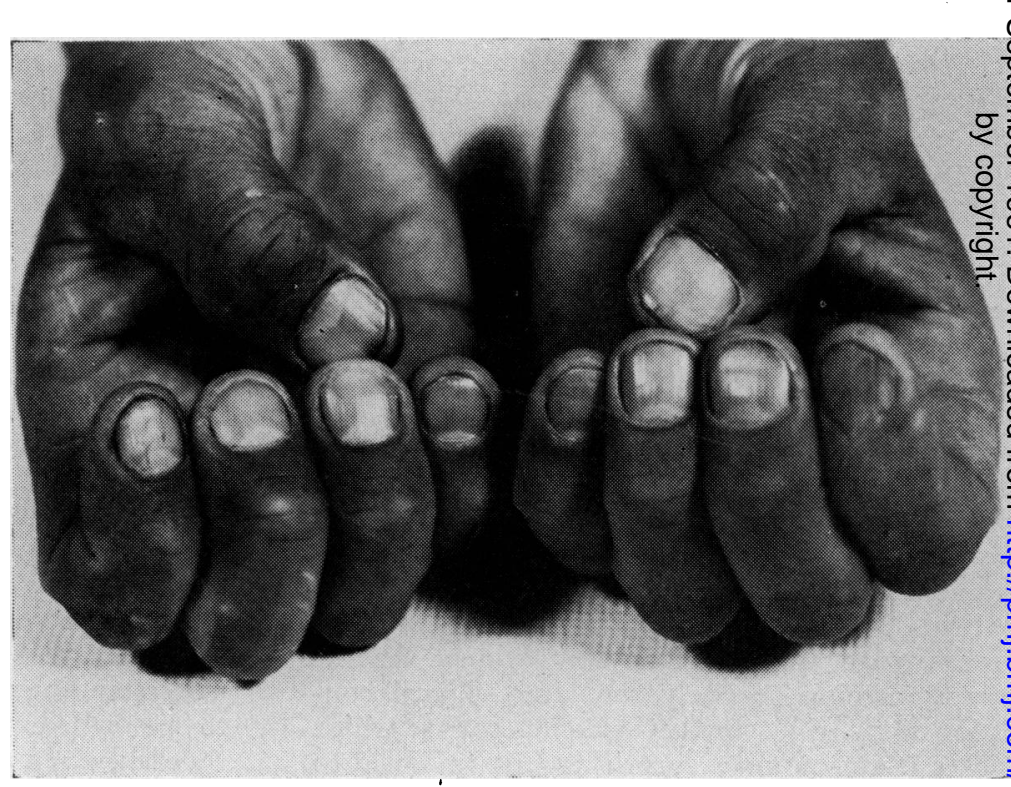

similar changes are seldom described in the toenails, nor have we observed them. The buccal mucosa is pale, atrophic and often the seat of leukoplakia; the tongue is atrophic and red (Fig. 3). Similar changes are evident in the pharynx and cesophagus and are often associated with fibrous bands or web-like strictures in the lower pharynx or upper œsophagus (Fig. 4). Atrophy of the gastric mucosa is often present and usually associated with achlorhydria. The spleen is palpable in about $20 \%$ of cases. Many patients have an associated hypochromic micro을 cytic anæmia, but its absence is not uncommon. N This is the clinical picture presented by patient with severe long-standing disease. Buf it is important to remember that the clinicad features are often much less evident. Most imo portant of all we have now come to recognize that anæmia is very often not in evidence.

It is now agreed that the Plummer-Vinson syndrome is the sequel of a long-standing depletion of body iron stores and there are two features of 


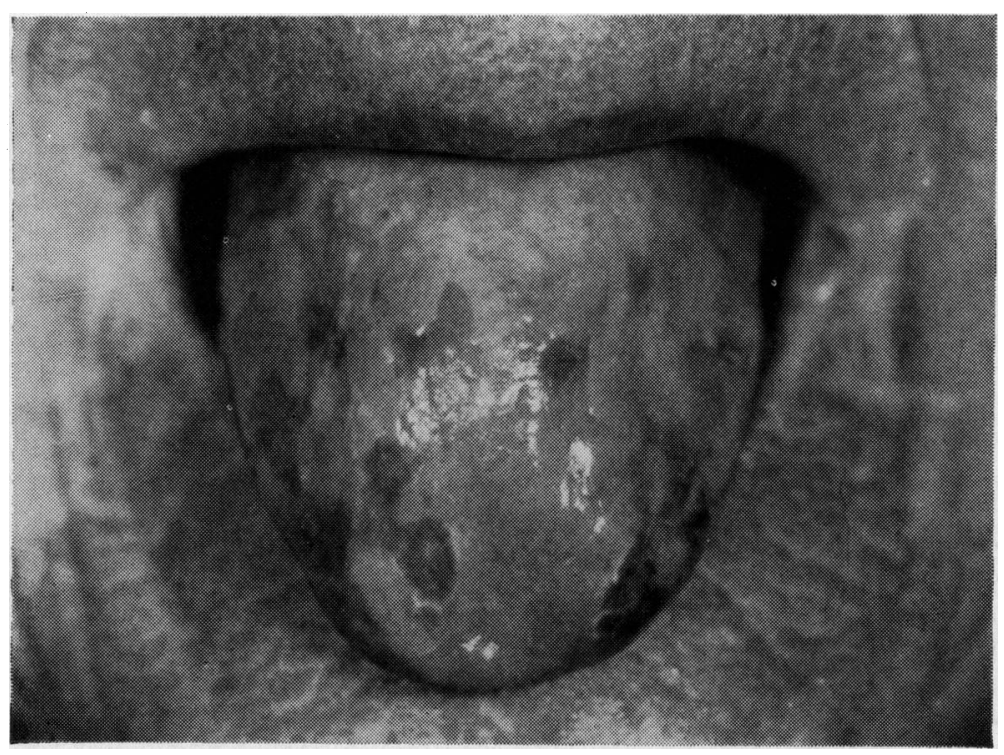

Fig. 3.-(Case 5) Atrophic mucosa and superficial ulceration of the tongue. The area of scarring on the left side of the dorsum of the tongue was the site of a squamous cell carcinoma treated by radon seed implantation three months prevoiusly

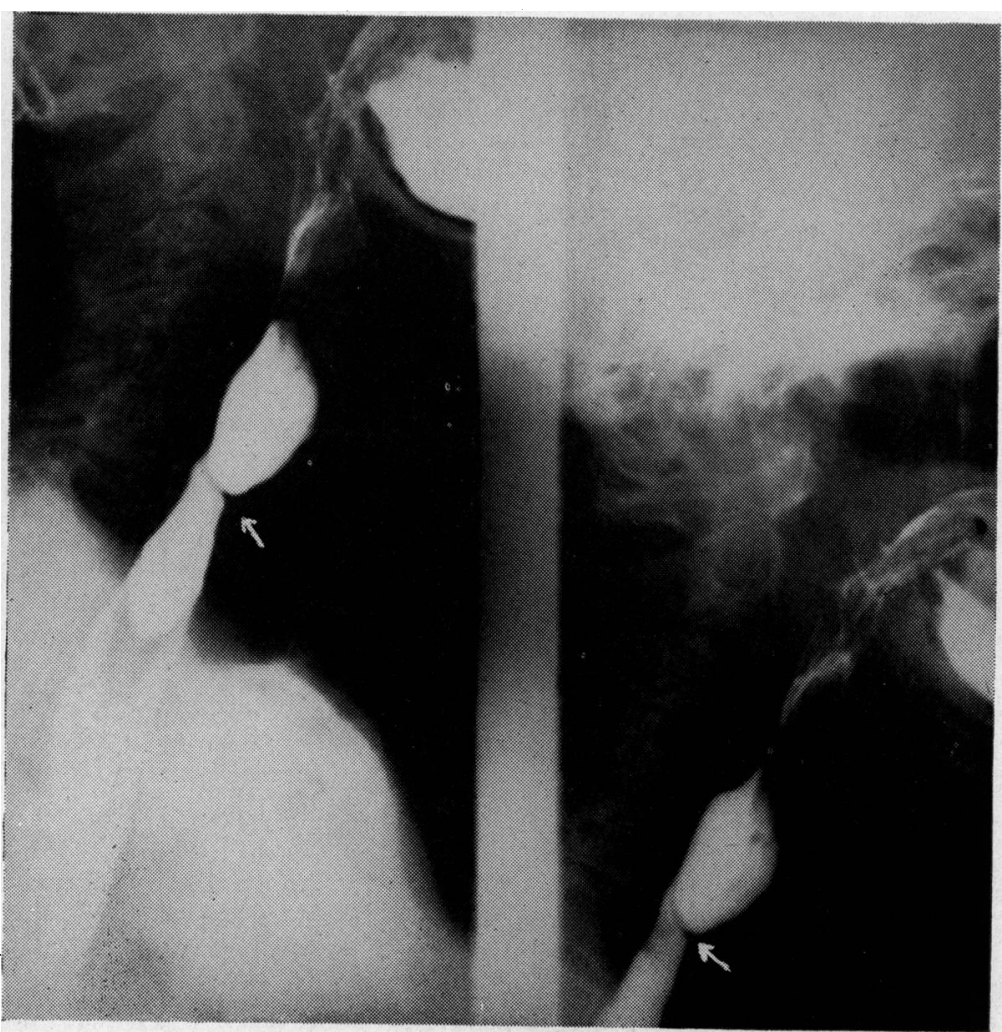

FIG. 4.-A thin fold in the upper cesophagus, arising anteriorly and stretching across the lumen -a typical web. 
the condition which are usually regarded as being essential for its diagnosis. They are, firstly, dysphagia associated with the characteristic mucosal lesions, and secondly, evidence of diminished body iron stores usually associated with low serum iron values and absence of stainable iron in the bone-narrow. It was the constant presence of these two features that led Waldenstrom and Kjellberg (1939) to introduce the term "sideropenic dysphagia' to describe the condition; this is a much more informative title and its use dodges the controversy in the eponymous description of this syndrome that has taken place over the years. In a recent review of Swedish cases, however, Wynder and Fryer (1958) state that many female patients, having the classical clinical stigmata of the Plummer-Vinson syndrome with or without cancer, have normal serum iron and hæmoglobin values when first seen. This somewhat surprising observation they attribute to the fall in iron requirements that follow the cessation of menstruation, the persisting tissue changes being presumably irreversible.

It was probably Logan Turner, of Edinburgh, who was the first to observe, in 1913, the neoplastic potential of the mucosal lesions seen in this syndrome. He described 68 cases of malignant disease of the cesophagus and remarked on the greater female incidence of carcinoma at the upper end compared with other levels in the œsophagus. He also commented on the often prolonged history of dysphagia in many of these women with carcinoma, and stated: 'These cases sufficiently illustrate the period over which symptoms produced by undoubted malignancy of the œsophagus may continue'. The average duration of the dysphagia in Logan Turner's female patients with hypopharyngeal carcinoma was five years. By 1920 Logan Turner had extended his observations to 140 cases of œesophageal carcinoma, 98 of whom were hypopharyngeal. Of these 98 , no less than 85 occurred in females. Whereas, in males, the average duration of the dysphagia was but a few months, the dysphagia in the females had in some cases been present for many years. Being by then aware of the writings of Paterson and Brown-Kelly, Logan Turner wrote: 'In most women whose period of symptoms is unusually prolonged, it is possible that a condition may exist which favours tumour development and is the cause of the obstruction in the earlier stages of the history'. Because of these observations, there seems little doubt that many of Logan Turner's patients had suffered from the PlummerVinson syndrome or sideropenic dysphagia. Paterson, in 1919, had remarked on ' . . . the not infrequent supervention in such cases of malignant disease at the mouth of the gullet', and Brown-
Kelly had noted a striking female sex preponder-气 ance in his cases of hypopharyngeal carcinoma.

It had thus become clearly apparent by this $\propto$ time that patients with the Plummer-Vinson syn- $C$ drome often developed hypopharyngeal or, as it $\overrightarrow{\vec{F}}$ is more often called, post-cricoid carcinoma.

However, it was not until 1936 that H. E. Ahlbom, from observations at the Radiumhemmet in Stockholm, produced convincing evidence of $\widetilde{\widetilde{\phi}}$ the development of cancer of the hypopharynx in patients with the Plummer-Vinson syndrome.

When in 1937 Ahlbom examined the records of $\vec{\circ}$ all the women treated at the Radiumhemmet for $\overrightarrow{\vec{\omega}}$ meso- and hypopharyngeal carcinoma from $1931 \stackrel{\circ}{\circ}$ to 1936 , he found that the Plummer-Vinson syn-8 drome was present in no less than $90 \%$. But he 3 . was also able to show from his experience (and $\omega$ this is an important fact which is often overlooked) that the risk of cancer developing was not $\stackrel{\omega}{-}$ confined to the post-cricoid area but affected also in the buccal mucosa, tongue, and all levels of the ${ }^{\omega}$ œsophagus.

The incidence of the Plummer-Vinson syn- $\vec{c}$ drome in Australia is probably little different $\mathbb{D}$ from that which obtains in the United Kingdom ${ }_{\mathbb{\Phi}}$ or in the North American continent and, largety 3 due to its infrequency, figures for its incidenge are not readily obtainable. We have, howeve्s, $\vec{\theta}$ been able to lay hands on a limited number of figures of the incidence of upper gastro-intestin tract carcinoma reported at the Central Cancero Registry, Melbourne, in the years 1950 to 1954 , and to compare them with the number reported from hospitals in Sweden, Denmark, the United Kingdom and the United States during the samea period (Table I).

The figures for Melbourne reveal approximately the same sex incidence as was observed in Denmark, the United Kingdom and North America; in contrast are the figures for Sweden $\frac{3}{3}$ which reveal a striking female incidence, especially at hypopharyngeal level.

Vidboek, in 1944, reviewed 1,313 cases of upper alimentary tract carcinoma in Denmark. The incidence of carcinoma of the pharynx ando œsophagus in females was only half that of Swedish women and this he attributed to theo lower incidence of Plummer-Vinson syndrome in Danish as compared with Swedish women. Onlyor six of his patients, all female, had evidence of $N$ this syndrome.

There is, therefore, reasonably convincing evidence that in women the Plummer-Vinson syn-o drome is an important ætiological factor in the causation of cancer of the mouth, pharynx and $\stackrel{\oplus}{+}$ csophagus. Certainly the incidence of cancer at 0 these sites in women parallels fairly closely the $\vec{P}$ 
TABLE I

Number of Cancer Patients and Percentage of Women with Cancer, by Site, at Hospitals in Australia, Sweden Denmark, England and The United States During I950-1954

\begin{tabular}{|c|c|c|c|c|c|c|c|c|c|c|}
\hline \multirow[t]{2}{*}{ Site } & \multicolumn{2}{|c|}{$\begin{array}{c}\text { Australia } \\
\text { Melbourne }\end{array}$} & \multicolumn{2}{|c|}{$\begin{array}{c}\text { Sweden } \\
\text { Radiumhemmet }\end{array}$} & \multicolumn{2}{|c|}{$\begin{array}{c}\text { Denmark } \\
\text { Radium Centre }\end{array}$} & \multicolumn{2}{|c|}{$\begin{array}{c}\text { England } \\
\text { Royal Marsden }\end{array}$} & \multicolumn{2}{|c|}{$\begin{array}{l}\text { United States } \\
\text { Memorial Centre }\end{array}$} \\
\hline & $\begin{array}{c}\text { No. } \\
\text { Patients }\end{array}$ & $\begin{array}{c}\% \\
\text { Women }\end{array}$ & $\begin{array}{c}\text { No. } \\
\text { Patient }\end{array}$ & $\begin{array}{c}\% \\
\text { Women }\end{array}$ & $\begin{array}{l}\text { No. } \\
\text { Patien }\end{array}$ & $\begin{array}{l}\% \\
\text { Vomen }\end{array}$ & $\begin{array}{l}\text { No. } \\
\text { Patien }\end{array}$ & $\begin{array}{l}\% \\
\text { omen }\end{array}$ & $\begin{array}{l}\text { No. } \\
\text { Patien }\end{array}$ & $\begin{array}{l}\% \\
\text { omen }\end{array}$ \\
\hline Lip & 334 & 19 & 249 & 9 & 200 & 12 & 33 & 15 & 219 & 7 \\
\hline Buccal Mucosa & 9 & 22 & 74 & $5^{I}$ & 34 & 35 & 16 & 25 & 8 & 37 \\
\hline Gingiva & 13 & 31 & 64 & 47 & 34 & 53 & 13 & 38 & 207 & 26 \\
\hline Palate & 26 & 27 & 28 & 50 & 27 & 37 & 31 & 19 & 160 & 23 \\
\hline Tongue & 94 & 27 & 164 & 45 & 99 & $4 \mathrm{I}$ & 82 & 22 & 549 & 30 \\
\hline Tonsil & 36 & 17 & 31 & 29 & 29 & 24 & 40 & 25 & 178 & 16 \\
\hline Naso-pharyn $x$ & 14 & 50 & 113 & 42 & $3^{1}$ & 26 & 72 & 25 & 154 & 27 \\
\hline Hypo-pharynx & 49 & 35 & 157 & 57 & 60 & 18 & I 18 & 30 & 349 & 8 \\
\hline Esophagus & 176 & 30 & 259 & 39 & 213 & 28 & 83 & 32 & 308 & 16 \\
\hline
\end{tabular}

(Based on Wynder, Hultberg, Jacobsson and Bross (1957))

frequency of the Plummer-Vinson syndrome, and this is strikingly borne out by the Swedish figures.

In spite of the relative infrequency of this syndrome in Australia we have within recent times treated patients suffering from cancer of the upper gastro-intestinal tract, each of whom had some or all of the stigmata of the Plummer-Vinson syndrome.

It seemed to us not inappropriate to give a short account of these five cases in an attempt to underline the importance of this syndrome as an ætiological factor in the causation of mouth cancer and the need to be constantly on the look-out for this complication in any patient with a long history of dysphagia with or without irondeficiency anæmia.

\section{Case Reports}

CASE I-Carcinoma of the Alveolus, Tongue, Palate, Hypopharynx

Mrs. C. H., an English migrant aged 65 years, was admitted to the Alfred Hospital in December 1960, under the care of Dr. J. Stubbe.

Five years before, whilst an inpatient in the London Hospital, she had complained of dysphagia and ulcers in the mouth of ten years duration. She was then found to have the characteristic facies of the Plummer Vinson Syndrome and her fingernails were flat and ridged. There was an ulcerating tumour involving both the floor of the mouth and the left mandible which was proven on biopsy to be an early infiltrating squamous cell carcinoma. Because of an extensive tissue reaction which developed before a course of radiotherapy could be completed, surgical excision of the tumour and left half of the mandible was performed.

Apart from continuing mild dysphagia she had re- mained well following this operation but was admitted to the Alfred Hospital with a short history of weakness, dyspncea, weight loss and increasing dysphagia.

She was pale and thin and had scarring at the angles of the mouth and leukoplakia of both upper and lower lips. Her operation scar was well healed and there was no hint of local or cervical lymph node recurrence. The buccal mucosa was pale and atrophic and the gums edentulous. The tongue was atrophic, bled easily and was surmounted by multiple white flat plaques 3 to 4 $\mathrm{mm}$. in diameter (Fig. 5). There was an irregular penetrating ulcer $1 \mathrm{~cm}$. in diameter on the soft palate. Her fingernails were brittle and ridged but not spoon-

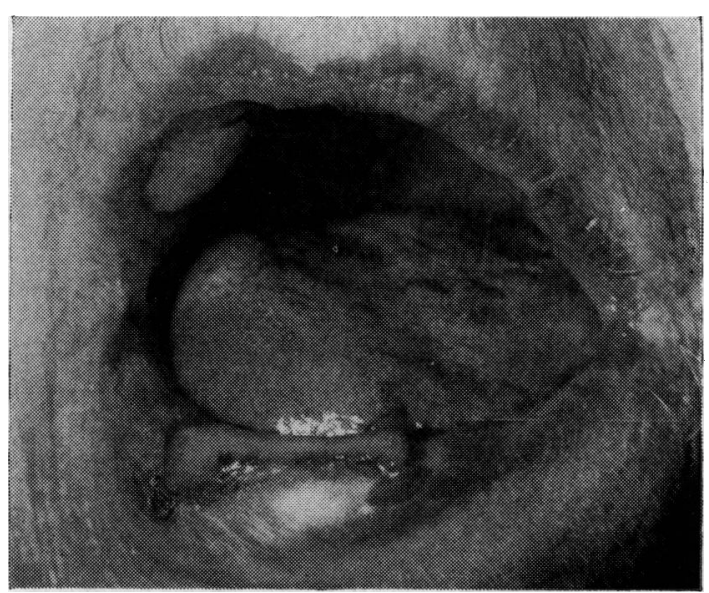

Frg. 5.-(Case I) Multiple raised plaques on the tongue which, on biopsy, proved to be squamous cell carcinoma. 
shaped; the spleen was not palpable but the liver was enlarged and irregular.

Investigations. Hæmoglobin $8 \mathrm{~g} . / 100 \mathrm{ml}$; blood film, hypochromic anæmia; serum iron, $25 \mu \mathrm{g} . / 100 \mathrm{ml}$.; stools positive for occult blood. Esophagoscopy (Mr. G. Stirling): at $14 \mathrm{~cm}$. from the alveolar margin there was a friable, fungating annular tumour preventing entry to the œsophagus. Biopsies of the lesions on the tongue, palate and hypopharynx showed well differentiated squamous cell carcinoma. Biopsy of the buccal mucosa showed atrophy with submucosal inflammatory cell infiltration.

A palliative course of radiotherapy was prescribed.

\section{CASE 2-Carcinoma of the Hypopharynx}

Mrs. E. B. aged 65 years was admitted to the Royal Melbourne Hospital on April 14, 1960, under the care of Professor R. R. H. Lovell.

From the age of 40 years or thereabouts she had experienced difficulty in swallowing, solid food appearing to stick at the level of the supra-sternal notch. During the previous year, she had become progressively more tired and short of breath on exertion. The dysphagia had increased in severity in the past three weeks.

Examination revealed a thin, pale woman with koilonychia and brittle nails. She was edentulous and had a red atrophic tongue and cracking at the angles of her mouth. The spleen was palpable.

Investigations. Hæmoglobin 5.9 g./100 ml.; blood film, erythrocytes hypochromic with anisocytosis; colour index 0.46 ; serum iron $16 \mu \mathrm{g} . / 100 \mathrm{ml}$; occult blood negative; bone marrow, hyperplastic with no stainable iron. X-ray: Barium swallow demonstrated an extensive irregular tumour of the hypopharynx extending into the upper œsophagus. This on biopsy proved to be a squamous cell carcinoma and a section taken from the mucosa adjacent to the lesion showed quite striking hyperkeratotic changes.

Operative treatment was considered inadvisable because of her poor general condition and she died two weeks after admission despite blood transfusion.

Autopsy revealed an extensive carcinoma of the hypopharynx extending into the upper œsophagus (Fig. 6). There were metastases present in adjacent lymph nodes and in the liver.

\section{CASE 3-Carcinoma of the Buccal Mucosa}

Mrs. J. B., aged 63 years, was admitted to the Royal Melbourne Hospital on October 19, 1956, under the care of Professor M. R. Ewing. For as long as she could remember she had found difficulty in swallowing solid foods. For one month she had suffered with tiredness and a painful tongue and recently a small ulcer had appeared near her lower gum.

She was a thin edentulous woman with atrophic glossitis and some small areas of leukoplakia on the lower alveolus. She had a firm, raised circular ulcerated lesion $3 \mathrm{~cm}$. in diameter in the right lower gingivobuccal sulcus encroaching on the right alveolus (Fig. 7). A single hard lymph node $\mathrm{I} \mathrm{cm}$. in diameter was palpable in the right submandibular region.

Investigations. Hæmoglobin $13 \mathrm{~g} . / 100 \mathrm{ml}$; blood film normal; W.R. negative. X-ray: Barium swallow revealed a web in the lower cervical cesophagus. Biopsy of lesion: squamous cell carcinoma of the buccal mucosa.

On October 10, 1956, an excision of this lesion with the right half of the mandible and a right-sided block dissection of the neck was performed. She remained well until January, 1957, when a left-sided submandibular

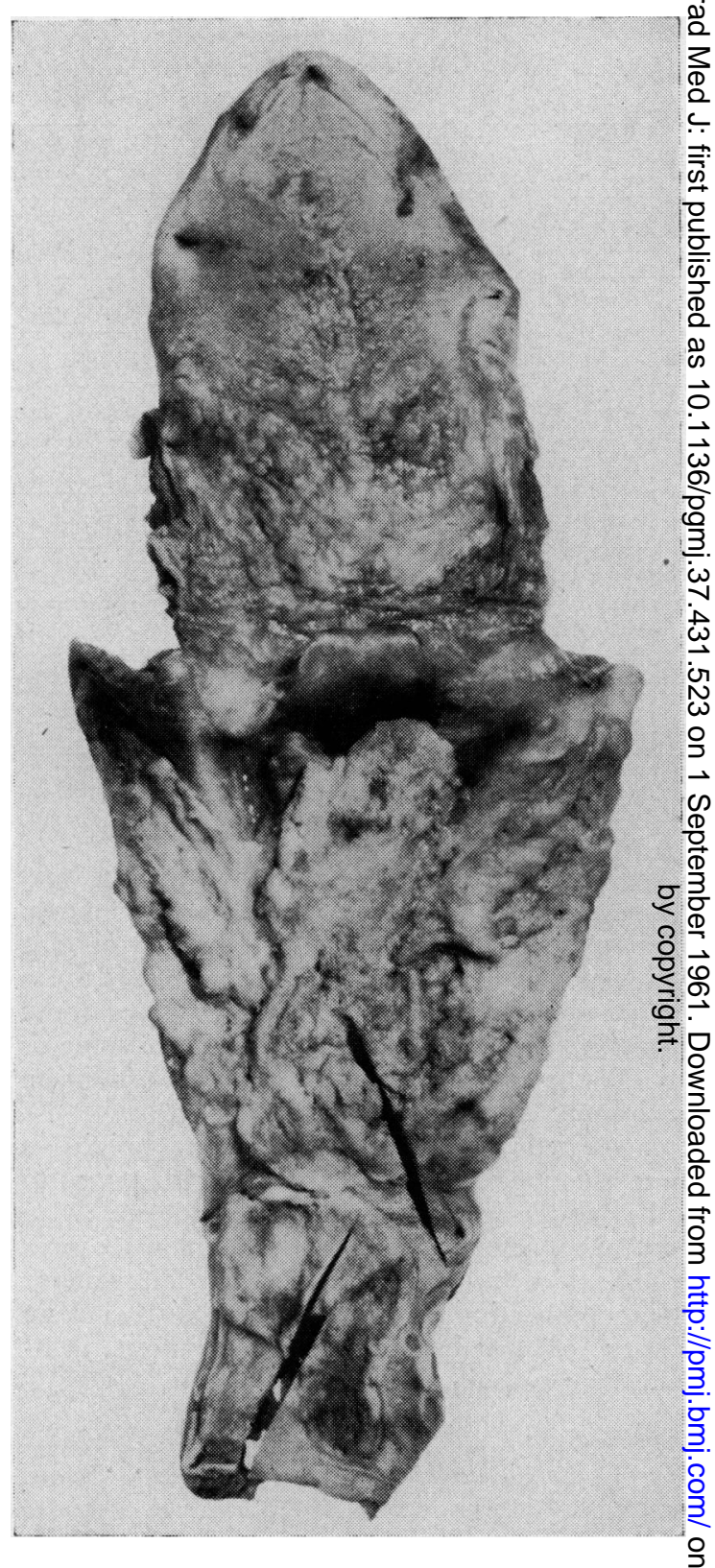

FIG. 6.-(Case 2) Autopsy specimen showing an ex $\rightarrow>$ tensive carcinoma of the hypopharynx and carcinoma of the upper œsophagus. recurrence necessitated a left-sided block dissection of
the neck.

Ten months after the original. excision she agait presented with a recurrence in the right parotid glande A course of deep X-ray therapy was commenced but she deteriorated and died on September $1,1957$.

Autopsy revealed secondary squamous cell carcinoma in the right parotid gland. 


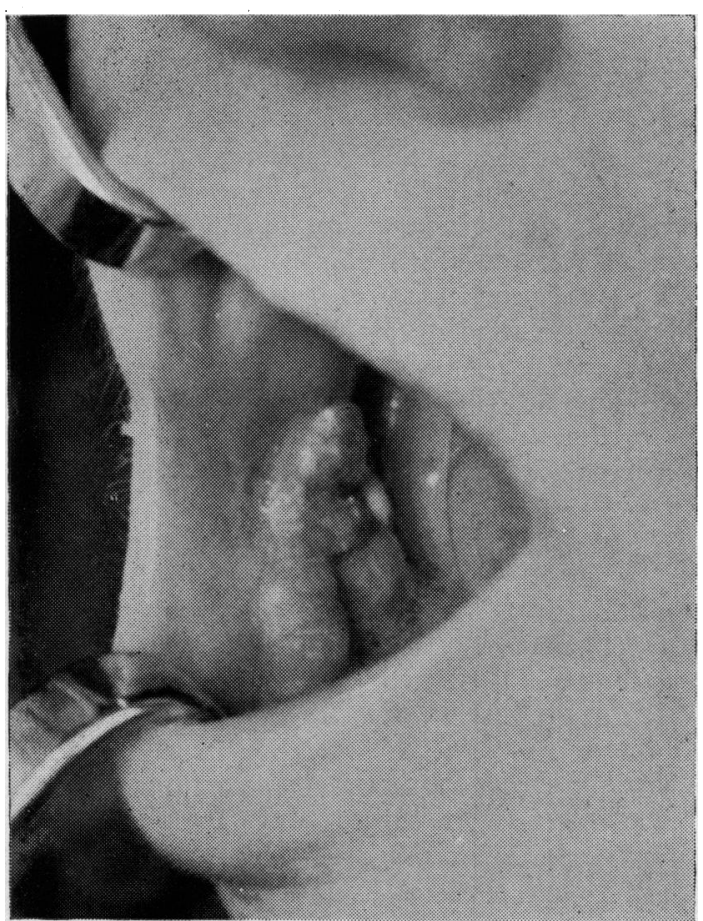

Fig. 7.-(Case 3) Carcinoma of the buccal mucosa.

\section{CASE 4-Carcinoma of the CEsophagus}

Mrs. M. M., aged 60 years, was admitted to the Alfred Hospital on March 1, 1957, under the care of Professor M. R. Ewing. For 17 years she had been unable to eat solid foods because of obstruction to swallowing at the level of the manubrium sterni. For five weeks she had suffered from lower sternal discomfort on eating, pain under the left costal margin, regurgitant vomiting, anorexia and loss of weight. Some years previously she had been given a blood transfusion because of anæmia.

Examination revealed a thin, pale, edentulous woman with a small mouth with angular scarring. She had a raw, smooth tongue and koilonychia.

Investigations. Hæmoglobin $9.7 \mathrm{~g} . / 100 \mathrm{ml}$; blood film, hypochromic red cells with anisocytosis; serum iron $35 \mu \mathrm{g} . / 100 \mathrm{ml}$. X-ray: Barium swallow revealed partial obstruction to the passage of barium due to a web at the level of the sixth cervical vertebra. There was also dilatation of the middle third of the csophagus and an irregular stricture in the lower third. Esophagoscopy (Mr. K. N. Morris): The entrance to the cesophagus was difficult to identify and a lesion in the nature of a web was ruptured before entering the cesophagus. At 35 $\mathrm{cm}$. a fungating tumour was visualized. Biopsy of this lesion proved it to be a well differentiated squamous cell carcinoma.

On March 21, 1960, a partial œsophago-gastrectomy was performed by Mr. K. N. Morris. The resected specimen revealed an extensive squamous cell carcinoma of the lower third of the cesophagus without spread to adjacent lymph nodes.

Now three and a half years later she remains well despite some mild residual dysphagia.

\section{CASE 5-Carcinoma of the Tongue}

Mrs. E. S., aged 64 years, was admitted to the Alfred Hospital on March 3, 1960, under Dr. J. McLean. For the past 17 years she had suffered with dysphagia, recently increasing in severity. Over this period a typical Raynaud's phenomenon had affected her hands and feet on exposure to cold. She had suffered for many years from anæmia resistant to treatment with Vitamin $B_{12}$. Over the previous year she had suffered from anorexia, mild loss of weight and a painful tongue.

Examination revealed a well nourished woman with sclerodactyly, brittle nails and tight, smooth facial skin. There was scarring at the angles of the mouth and a raw smooth tongue with shallow and non-indurated ulceration on the left side of the dorsum measuring $1 \mathrm{~cm}$. by $2 \mathrm{~cm}$. in diameter (Fig. 3). There was no palpable cervical lymph nodes.

Investigations. Hæmoglobin $13.8 \mathrm{~g} / 100 \mathrm{ml}$.; blood film normal; serum iron $40 \mu \mathrm{g}$./100 ml.; Wassermann negative; Schilling test normal; Histamine test meal, achlorhydria; stools negative for occult blood. X-ray: barium swallow revealed a small web in the post cricoid region. There was also dilatation of the lower third of the cesophagus and a stricture at the lower end. Esophagoscopy: fibrous stricture $5 \mathrm{~mm}$. in diameter dilated at pharyngo-œsophageal junction. Benign stricture at lower end of csophagus. Gastric mucosa atrophic. Biopsy of ulcer on tongue: well differentiated squamous cell carcinoma.

The dysphagia was subsequently relieved by the regular passage of bougies. In June, r960, radon seeds were implanted into the tongue lesion after she had refused any major operative procedure.

\section{Discussion}

The important points that now emerge for discussion are:

(a) What is the ætiology of this condition?

(b) What is the nature of the lesions in the upper alimentary tract ?

(c) Is the condition preventable or are the established lesions reversible?

\section{(a) What is the atiology of this condition?}

As in the case with many other disease complexes, controversy has existed over the true ætiology of this syndrome.

Streptococcal infection (Hurst, 1926), tertiary syphilis, vitamin deficiency, hysteria (Vinson, 1922), and 'gastric inadequacy' (Suzman, 1933) have all, at some time, been suggested as possible causes. Dysphagia was once considered to be the primary factor, the resulting inadequate oral intake being held responsible for the secondary deficiencies. The passage of œsophageal bougies alone, however, 'although it may be effective in the relief of dysphagia and in the amount and variety of oral intake, has been shown to lead to little or no improvement in the condition (Johnson, I93I). The commonly associated achlorhydria and gastric atrophy led to the suggestion that the primary defect was that of ' gastric inadequacy'. It has, however, subsequently been shown that the presence of acid in the stomach is only of minor 
importance in iron absorption. Nevertheless, it may assume greater importance when the iron in the diet is only just sufficient for daily needs. Witts (193I) treated his patients with liver, hydrochloric acid and multiple vitamins and found that the lesions did not improve. This was in direct contrast to the rapid response with iron therapy. Treatment with riboflavine alone has been found to improve only the oral fissures (Hurst, 1926).

There is now little doubt that the degenerative changes in the mucous membranes of the upper gastro-intestinal tract associated with the Plummer-Vinson syndrome are primarily caused by a prolonged iron deficiency. Most of the evidence for this has been of an indirect nature, that is the observed resolution of many of the lesions with iron administration (Witts, 1931; Suzman, I933; Andersson, 1955; Waldenstrom, 1938). Vinson (1922) had treated his dysphagic female patients with iron, arsenic, and œsophageal bouginage and remarked on the rapid improvement in the symptoms and blood picture. There is good evidence that iron usually produces a rapid resolution of the nail and epithelial changes (Figs. I, 2), but less often is there any lessening of the dysphagia.

It is observed that this syndrome occurs almost always in females and rarely in males. This is readily explained by the increased iron requirements of the female during menstruation, pregnancy and lactation. Many of these women live on a diet which is marginal in iron content and the increased requirements during reproductive life predispose to the development of iron deficiency. Since 1938 the Swedish Public Health Service has sponsored the fortification of white flour with iron and vitamin $B$, and '.. it is now a widely held clinical impression in Sweden that Plummer-Vinson syndrome is becoming a progressively rarer entity' (Wynder and Fryer, 1958).

It is believed that iron deficiency produces a generalized disturbance affecting the whole organism and that the deficiency is most evident in the tissues where cells are constantly being regenerated (Demulder, 1958). Changes are readily observed, for example, in the bone-marrow (disturbed cell maturation), skin and its appendages (koilonychia, smooth facial skin with oral angular fissures), and mucous membranes (buccal cavity, tongue, pharynx, œsophagus, stomach). The small intestinal mucosa, where mitosis is so active, however is usually not affected (Rawson and Rosenthal, I960).

Iron is present in the body chiefly as hæmoglobin and myoglobin, but is also an essential component of the intracellular enzymes catalase, peroxidase and the cytochromes. All these enzymes play an essential role in the transport and utilization of oxygen for energy requirements.
Beutler (1957, 1959) has shown experimentally气 that, in rats made iron deficient by bleeding, 3 specific intracellular iron-containing enzyme defi $-\mathbb{Q}$ ciencies occur in some organs. These enzyme de -\ulcorner ficiencies have not been shown to occur in the altered mucosal cells in human patients with chronic iron deficiency, but metabolic studies of excised 'precancerous' leukoplakic mucosa sug $\overline{\bar{n}}$. gest an abnormal pattern of oxidative mechanism before carcinoma develops (Weisberger, 1957). ㅇ

If these deficiencies of iron-containing enzymess do in fact occur, the subsequent neoplastic change $\overrightarrow{0}$ in the mucosa may be explained by the theory of Warburg (1956), who states that the first phase inf the origin of a carcinoma cell is the irreversibles injuring of respiration followed by a long struggle for existence of injured cells, those surviving. replacing the lost respiration energy by fermentation energy and, in so doing, becoming de-ct differentiated to a neoplastic cell.

(b) What is the nature of the lesions in the uppero alimentary tract?

The microscopic features of the atrophic mucouses membranes seen in this disease were first describedo by Paterson (1919) and later by Suzman (1933). $\frac{\mathbb{D}}{3}$

In general, all the epithelium from the mouth foo the lower osophagus is atrophic but, in magy areas, shows evidence of increased cellular active $\overrightarrow{4} \overrightarrow{0}$ in the basal layers with superficial hyperkeratogis?or leukoplakia (Figs. 8, 9) (similar to the skino lesion seen after initial applications of a car $\frac{O}{\Sigma}$ cinogen).

The tongue mucosa is usually smooth anda devoid of papillæ (Fig. 3). Throughout the areaso of atrophic mucosa there is submucosal infiltra tion with inflammatory cells. In the asophagus? this infiltration often extends into poorly developed muscle coats which are often partlyo replaced by connective tissue (Fig. 8). In addition, further changes commonly occur in the lower pharynx or upper œsophagus. Most frequently this is the characteristic and often radio- 3 . logically demonstrable web, a thin fold usuallyo arising anteriorly and stretching a variable 3 distance across the osophageal lumen (Fig. 4).0 Hoover (1935) biopsied these webs and found them to be composed of two mucous membraneo layers with minimal intervening fibrous tissue The obstructing lesion is often more extensive- o either a narrow circular constriction of the lumen $N$ or rarely an elongated csophageal stricture. There is commonly present an associated atrophyo of the gastric mucosa with submucosal cellular infiltration. However, the small intestine shows no macroscopic or microscopic changes (Rawson $\stackrel{5}{+}$ and Rosenthal, 1960).

The neoplastic changes that commonly arise 


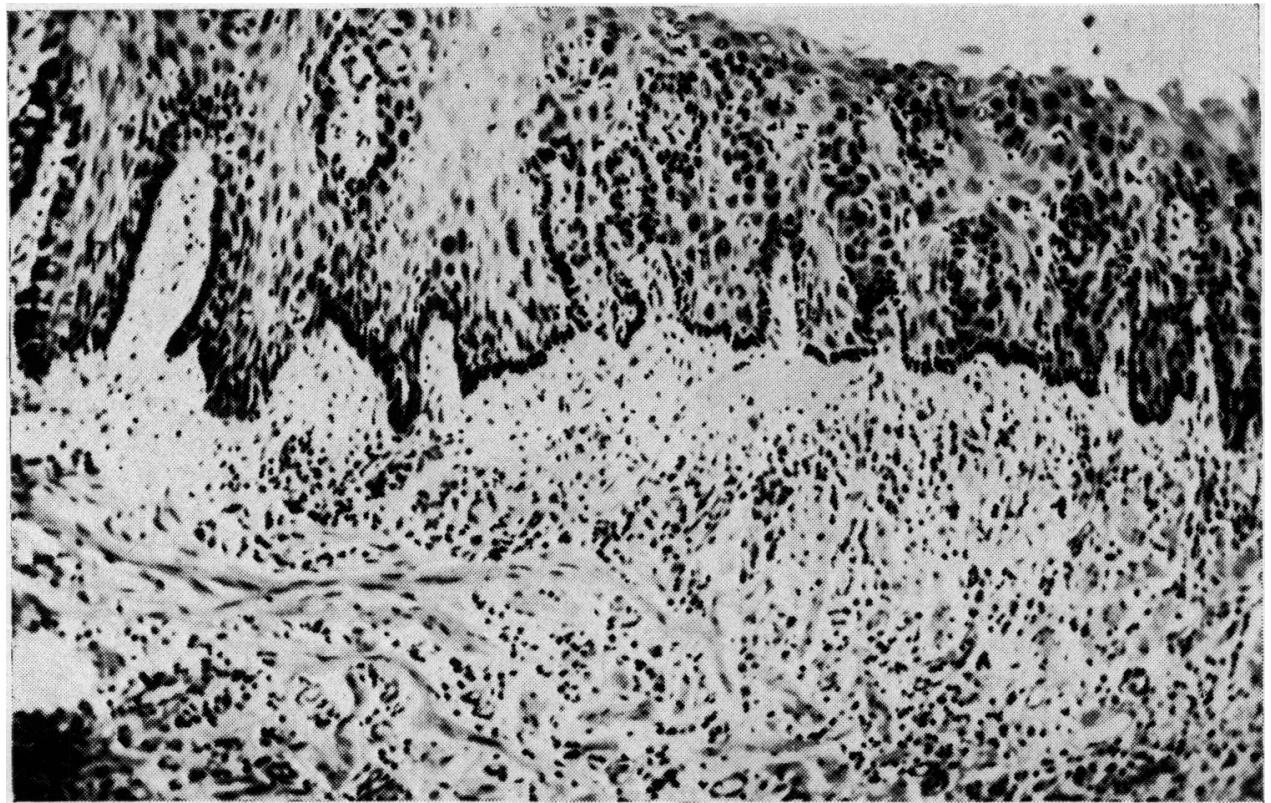

FIG. 8.-(Case 4) Biopsy of the cesophagus. Leukoplakia of the œsophageal mucosa and submucous

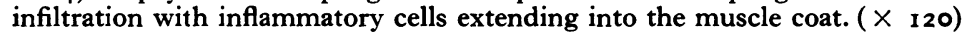

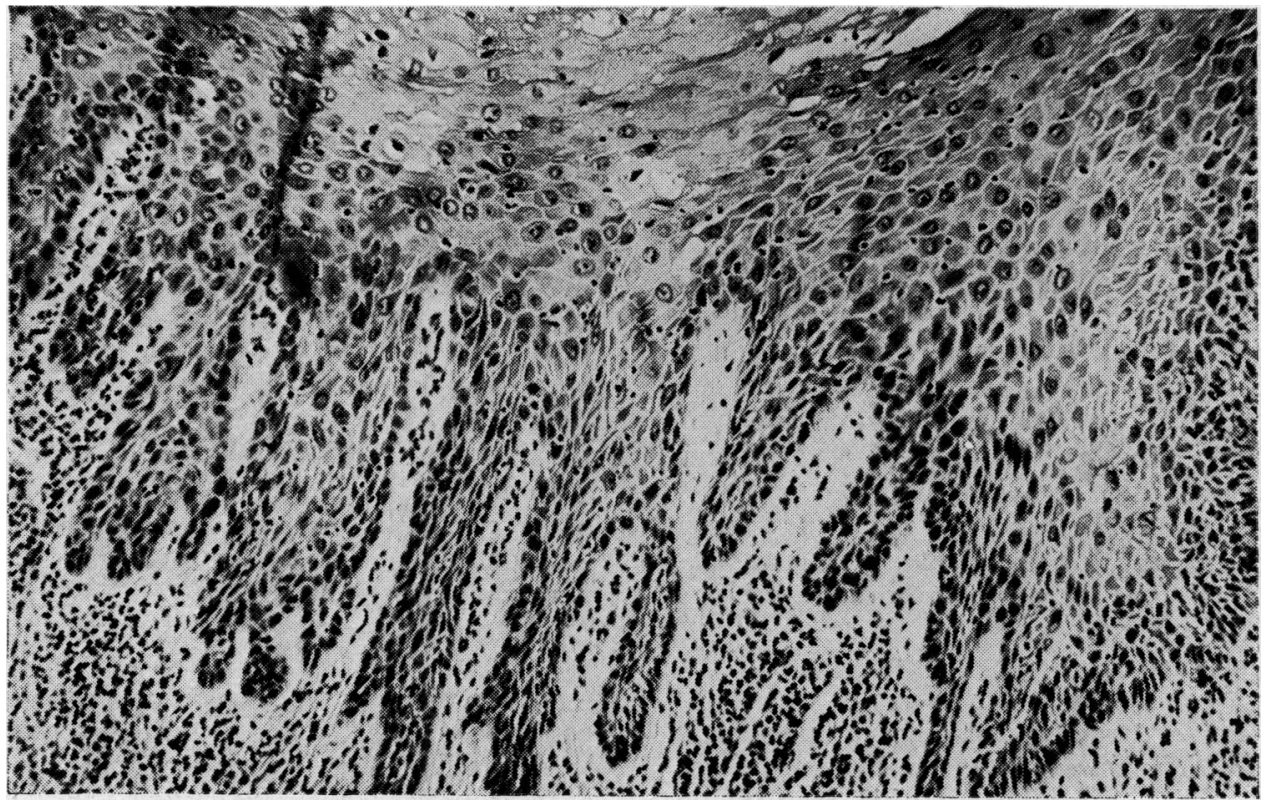

Fig. 9.-Biopsy of buccal mucosa in Plummer-Vinson Syndrome. Leukoplakia of the mucous membrane. Submucous inflammatory cell infiltration. ( $X$ 1 70) 
in the mucosa at any level from the mouth to the lower œsophagus are stated to occur in approximately $10 \%$ of patients with established PlummerVinson syndrome (Wynder, Hultberg, Jacobsson and Bross, 1957), most commonly at hypopharyngeal level but sometimes simultaneously at multiple sites (as in Case I). The carcinoma developed is always of squamous-cell variety but with varying degrees of differentiation.

After a study of patients developing carcinoma in association with web and stricture formation, Lindvall (1953) concluded that malignant degeneration did not occur at the site of these structural changes but in areas adjacent to them.

\section{(c) Is the condition preventable or are the established lesions reversible?}

Many writers have commented on the reversibility of many of the lesions of Pummer-Vinson syndrome following the administration of iron. If anæmia is present there is an immediate hæmatological response-the fingernails become normal (Figs. 1, 2) and even the atrophic lingual and buccal mucosa may be restored to normal.

The commonly present achlorhydria, especially in older women, is not reversible (Lancet, 1960). Lees and Rosenthal (1958) carried out gastric biopsy before and after correction of the blood picture with iron in patients with iron deficiency anæmia and found that the gastric mucosal lesions of infiltration and atrophy did not improve, and in some cases progressed.

Dysphagia may be improved following the administration of iron even without œsophagoscopy or bouginage but, if any radiological changes are present in the œsophagus, these usually persist.

However, it is a common observation that somewhere in the course of the disease the characteristic mucosal lesions become irreversible, even with prolonged treatment. It is probable then, that only in the early stages of the disease when the epithelial lesions are reversible, can therapy with iron prevent the later malignant changes. Weisberger (1957) stated that the treatment of the anæmia in 18 cases with Plummer-Vinson syndome had no effect on the eventual development of carcinoma. Also, of eight patients with this syndrome observed by Lindvall (1953) and known to have had previous iron therapy, seven developed carcinoma at some later stage in the disease.

We may then argue that a prolonged iron deficiency ' conditions' the mucosa of the upper gastro-intestinal tract producing a neoplastic potential which at some stage becomes irreversible. The prevention of this irreversible change would then depend ideally on the prevention of iron deficiency or, if iron deficiency occurs, on its early diagnosis and on the con tinued replenishment of the depleted iron stores? There is as yet no evidence to prove whether of not the incidence of subsequent neoplasia can be influenced by adequate iron therapy once irreversible, but still benign changes have occurrees Therefore, energetic treatment which in anw event improves many of the symptoms associate with the Plummer-Vinson syndrome should b b. instituted in all cases.

Endoscopic examination of the œsophagus if essential in all patients, and for three reasons:(I) to exclude other causes of the dysphagia? (2) to exclude any malignant change in the cesophagus; and (3) therapeutically to improve the dysphagia which is often severe and dise tressing. Even apparently innocent lesions shoul . be biopsied. In one of our patients carcinoma of the tongue was discovered on biopsy of a nonis indurated superficial ulceration.

Because of the risk of the development of cancer, all patients with the Plummer-Vinsob syndrome should be kept constantly under review so that if malignant change occurs, early diagnosis and treatment can be instituted.

\section{Summary}

It is now reasonably evident that the changes observed in patients with Plummer-Vinson s drome (or sideropenic dysphagia) are caused bs long-standing depletion of body iron storesp The evidence for this is, firstly, the diminished marrow and serum content of iron, and secondly $\bar{\partial}$ the observed retrogression of many of the classicat features of the disease following the therapeutie administration of iron. It is important to realize that anæmia may be absent, even in long-standing disease.

Invariably there are atrophic mucous mem brane changes present throughout the uppes gastro-intestinal tract and, in the early stages of the disease, these changes are reversible with iron administration. However, in the absence of treatment, these mucosal changes become irreversible and, in many patients, malignant de generation occurs. This malignant change canf occur not only at hypopharyngeal level but at any or multiple sites in the mouth, tongue? pharynx or œsophagus.

Diagnosis should be possible before these irre versible changes have occurred and, at this stage $?$ the later malignant changes can be prevented byc continued replenishment of the iron stores. If long-standing disease is present, the possibilityo of later malignant change must be borne in mind so that early diagnosis and treatment can be instituted. 
I wish to thank Professor M. R. Ewing for assistance in the preparation of this paper and Professor R. R. H. Lovell and Dr. J. Stubbe for permission to publish details of patients under their care.
I also acknowledge the assistance of Dr. N. A. Davis with the pathology, and Miss C. J. McCall and Mrs. J. C. Higginbottom of the Central Cancer Registry, Melbourne for the statistics included in Table $\mathbf{I}$.

\section{REFERENCES}

Анцвом, H. E. (1936): Simple Achlorhydric Anæmia, Plummer Vinson Syndrome and Carcinoma of the Mouth. Pharynx and Oesophagus in Women, Brit. med. $\mathcal{F}$., ii, 331.

Анцвом, H. E. (1937): Prädisponierende Faktoren für plattenepithelkarzinom in mund, hals und speiseröhre Eine statistische untersuchungam material des Radiumhemmets, Stockholm. Acta radiol (Stockh.), 18, 163.

Andersson, N. S. E. (1950): Experimental and Clinical Investigations into the Effect of Parenterally Administered Iron, Acta. med. scand. Supp., 90, 380.

Beutler, E. (1957): Iron Enzymes in Iron Deficiency: Cytochrome C, f. clin. Invest., $36,874$.

(1959): Iron Enzymes in Iron Deficiency: Aconitase Activity and Citrate Metabolism, $\mathcal{H}$. clin. Invest., 38, 1605.

Brown Kelly, A. (1919): Spasm at the Entrance to the Esophagus, $\mathcal{F}$. Laryng, 34, 285.

Demulder, R. (1958): Iron, A.M.A. Arch. intern. Med., 102, 254.

Hoover, W. B. (1935): The Syndrome of Anæmia, Glossitis and Dysphagia; New Engl. F. Med., $213,394$.

Hurst, A. F. (1926): The Plummer-Vinson Syndrome (Spasm of the Pharyngo-Esophageal Sphincter with Anæmia, and Splenomegaly), Guy's Hosp. Rep., 76, 426.

Johnson, R. S. (I93I): In discussion on ' Obstruction of the Upper End of the CEsophagus', Proc. roy. Soc. Med. 24, 1206.

Lancet (1960): Leading Article, ii, 27.

Lees, F., and Rosentral, F. D. (1958): Gastric Mucosal Lesions Before and After Treatment in Iron Deficiency Anæmia, Quart. F. Med., 27, 19.

Lindvall, N. (1953): Hypopharyngeal Carcinoma in Sideropenic Dysphagia, Acta radiol. (Stockh.), $39,17$.

Logan TURNer, A. (1913): Malignant Disease of the CEsophagus with Special Reference to Carcinoma of the Upper End: a Clinical Study based upon an Analysis of 68 cases of Tumour, $\mathcal{F}$. Laryng., 28, 281. (1920): Carcinoma of the Post Cricoid Region and Upper End of the CEsophagus, Ibid., 35, 34.

Paterson, D. R. (19r9): A Clinical Type of Dysphagia, Ibid., 34, 289.

Rawson, A., and Rosenthal, F. D. (1960): The Mucosa of the Stomach and Small Intestine in Iron Deficiency, Lancet, $\mathrm{i}, 730$.

Savilahti, M. (1946): On the Pathologic Anatomy of the Plummer Vinson Syndrome, Acta med. scand., 125, 40.

Suzman, M. M. (1933): Syndrome of Anæmia, Glossitis and Dysphagia, Arch. intern. Med., 51, 1.

VidBoek, A. (1944): Solitary and Multiple Carcinomas of the Upper Alimentary Tract, Acta Radiol., $25,339$.

Vinson, P. P. (1922): Hysterical Dysphagia, Minn. Med., 5, 107.

Waldenstrom, J. (1938): Iron and Epithelium: some Clinical Observations, Acta med. scand., Supp. $90,380$.

- and KJellberg, S. R. (1939): The Roentgenological Diagnosis of Sideropenic Dysphagia, Acta radiol., $20,618$.

Warburg, O. (1956): On the Origin of Cancer Cells, Science, 123, 309.

Weisberger, D. (1957): Precancerous Lesions, Y. Amer. dent. Ass., 54, 507.

WitTs, L. J. (1931): The syndrome of Glossitis, Dysphagia and Anæmia, Guy's Hosp. Rep., 8r, 193.

Wynder, E. L., Hultberg, S., Jacobsson, F., and Bross, I. J. (1957): Environmental Factors in Cancer of the Upper Alimentary Tract, Cancer (Philad.), ro, 470.

- and FrYer, J. H. (1958): Etiologic Considerations of Plummer Vinson (Paterson-Kelly) Syndrome, Ann. intern. Med., 49, iro6. 